
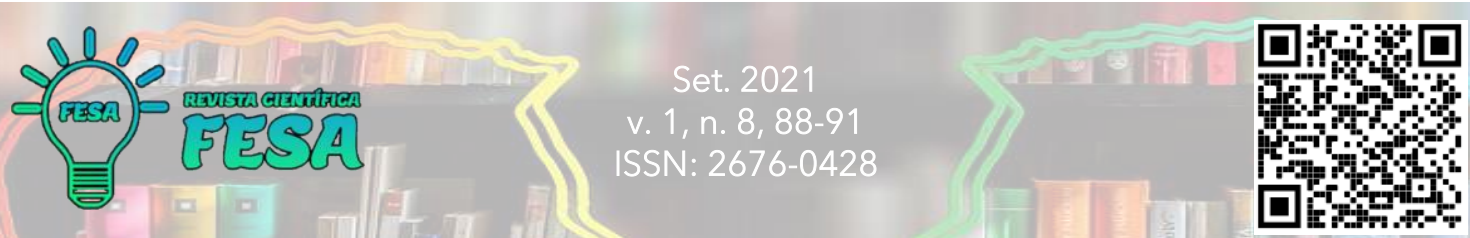

\title{
DESCORTINANDO O LETRAMENTO: RESENHA DO TEXTO MODELOS DE LETRAMENTO E AS PRÁTICAS DE ALFABETIZAÇÃO NA ESCOLA DE ANGELA KLEIMAN
}

KLEIMAN, Angela. Modelos de letramento e as práticas de alfabetização na escola. In: (Org.) Os significados do letramento: uma nova perspectiva sobre a prática social da escrita. Campinas: Mercado de Letras, 1995. p. 15-61.

Juliana Behrends de Souza Cerqueira ${ }^{1}$

Angela Kleiman é autora de numerosos e importantes trabalhos sobre leitura e alfabetização de adultos. As temáticas leitura e letramento são as suas principais áreas de pesquisa, com escopo principal o letramento do professor. $O$ texto "Modelos de letramento e as práticas de alfabetização na escola" é de grande importância para a formação do docente com vista à reflexão da prática em sala de aula. Essa área de pesquisa tem sido objeto de estudo de diversos autores contemporâneos, devido à necessidade de se melhorar a formação do professor e consequentemente a qualidade do ensino.

Desde o início de seu texto, a autora busca difundir o conceito de letramento e diferenciá-lo da prática da alfabetização. Inicia com um embasamento histórico e afirma que a temática do letramento é relativamente nova. Relata que por meio da difusão dos estudos sobre esse tema que frearemos a contínua segregação de grupos sociais que desconhecem a escrita ou não a usam frequentemente nas suas práticas sociais. Ressalta a relação direta das grandes mudanças sociais, políticas, cognitivas e econômicas com a propagação da escrita, reforçando a consolidada ideia de supremacia ligada à escrita.

A dicotomização dos termos letramento e alfabetização está presente em todo o texto. A autora apoia-se em o Heath $(1982,1983)$ e Rojo (1995) para definir letramento e o delimita como "uma prática discursiva de determinado grupo social, que está relacionada ao papel da escrita para tornar significativa essa interação oral, mas que não envolve, necessariamente, as atividades específicas de ler ou de escrever". Já quando busca precisar o termo alfabetização, limita-o apenas como

\footnotetext{
${ }^{1}$ Mestrado em Língua Portuguesa pela Universidade Federal Rural do Rio de Janeiro, Brasil(2018) Professor EBTT do Colégio Pedro II , Brasil
}

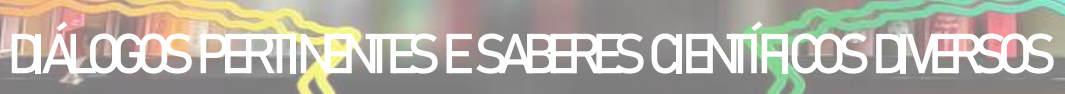



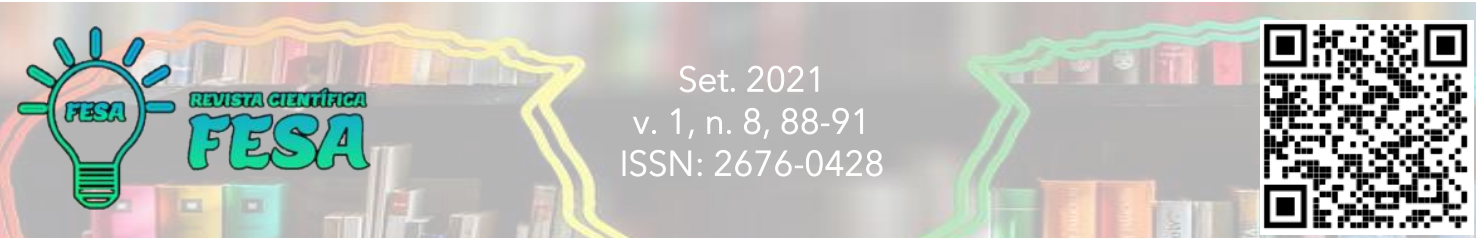

um tipo de prática de letramento, tratando-o como um mero o processo de aquisição de códigos (alfabético, numérico) de competência individual. Em linhas gerais, entende-se que alguém letrado não apenas sabe ler e escrever, mas cultiva e exerce as práticas sociais que usam a escrita e alguém alfabetizado aprendeu apenas a ler e a escrever.

O motivo da não sinonimização entre os termos, letramento e alfabetização, fundamenta-se na premissa de que uma pessoa pode ser considerada letrada, ainda que ainda não domine a leitura e a escrita, ou seja, mesmo não estando alfabetizada, faz uso da escrita como prática social. É válido destacar que a autora não despreza a alfabetização em prol do letramento. Ambos são processos interdependentes e indissociáveis devem ser trabalhados juntos, por isso a negativa da sinonimização dos termos fez-se necessária.

Baseada nos estudos de Street (1984), apresenta duas perspectivas de letramento: um denominado modelo autônomo e outro ideológico. No primeiro, ressalta-se a leitura como uma competência individual, meramente decodificadora de caracteres linguísticos. Demonstra preocupação, pois indubitavelmente é esse primeiro modelo que é adotado na escola, reconhecida historicamente como a mais importante agência de letramento. Informa, ainda, que ele reproduz práticas que privilegiam o aprendizado das classes majoritárias e apresenta impacto negativo nas minoritárias, por desprezar as práticas de letramento extraescolares. Em tempo, sai em defesa do modelo ideológico que apresenta objetivos mais amplos, pois aqui a escrita tem significado, tem função social, é indicado para que se repense o fazer pedagógico. Defende a leitura como prática social e considera a diversidade cultural como ponto positivo a ser respeitado. Apresenta exemplos comprobatórios, de que esse modelo foi pensado para oportunizar o letramento às classes minoritárias, por dar voz às práticas de letramento extraescolares.

Características do modelo autônomo de letramento são apresentadas. Dentre elas, destacam-se as relações escrita $x$ desenvolvimento cognitivo, oralidade x escrita e a valorização da escrita, prestigiando os grupos sociais que possuem sua cultura baseada na mesma. Ao relacionar o letramento à cognição, a autora fez uso de comparação grupos letrados e não letrados, porém alerta que tal comparação pode fornecer argumentos para o preconceito. No que tange oralidade e escrita, percebe-se que ambas devem ser inseridas em um contínuo, 

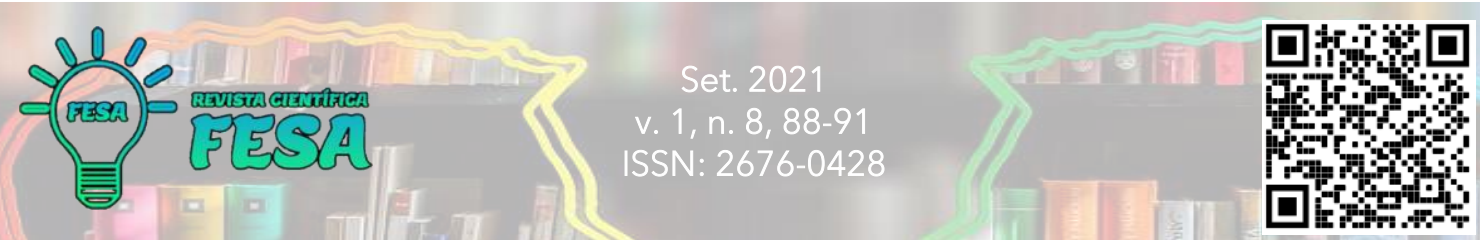

afastando-se da ideia de polarização que as coloca em lados opostos. Ressalta que tanto uma como outra provém de práticas coletivas. Enfim, é analisado o poder transformador da escrita, afirmando que por meio dela o indivíduo pode ser considerado cognitivamente superior a outro, reforçando a ideia de segregação e preconceito, dando à escrita uma perigosa supremacia. Kleiman apoia-se no conceito de Graff (1979), ao usar a expressão "mito do letramento" que se trata de uma visão na qual a ascensão social se faz por meio da escrita. O conceito é desmitificado, pois não há dados que comprovem realmente que alguém pode ser socialmente superior a outro só por fazer uso social da escrita. Por vezes, o próprio indivíduo atribui a si mesmo a culpa por fazer parte de um grupo economicamente minoritário. Tal consequência é gerada pelo modelo autônomo de letramento, que não traz culpa do fracasso para o próprio processo e sim para o indivíduo que não alcançou as expectativas de um modelo fragmentado e sem significado.

Já no modelo ideológico, Kleiman opta por uma abordagem pautada no empirismo. Com base nos estudos de Heath $(1982,1983)$, introduz a ideia do evento de letramento, que são atividades empiricamente constituídas com o apoio da escrita, ou seja, são situações que utilizam a escrita como suporte. Apresenta diversas práticas discursivas e eventos de letramento. Destaca a importância das agências sistemáticas e assistemáticas de letramento, como exemplo daquelas temos as escolas e destas as igrejas, as famílias, as ruas, entre outras. Aponta a alfabetização de adultos como uma atmosfera potencialmente conflitiva devido à tentativa feita por alguns profissionais de substituição dos valores trazidos pelos alunos pela cultura social dominante. A preparação do profissional de educação ao lidar com esses grupos específicos é necessária.

Finaliza com a tentativa de desconstruir a imagem de que o não alfabetizado não possui inteligência e reforça a existência de grupos resistentes à inserção na cultura letrada. Para esses grupos, o modelo ideológico é a saída, em razão de afirmar que as práticas letradas são determinadas pelo contexto social abrindo espaço para a sua própria cultura, renegando os costumes universalmente prestigiados.

Ao fazer contrapontos entre o modelo autônomo e o ideológico de letramento, a autora posiciona-se a favor do segundo. Algumas vezes, opta pelo não aprofundamento na definição do primeiro e explora os aspectos positivos do 
segundo, reforçando sua parcialidade. Apesar do texto ter sido escrito em 1995, suas ideias são claras, coerentes e condizem com o cenário educacional atual. Reforçando a ideia de que muito ainda há de ser feito, pois em duas décadas o cenário educacional do nosso país pouco mudou.

A obra apresenta um texto denso e com vocabulário específico. Por vezes, a leitura deve ser retomada para garantir a plena compreensão do texto. Os períodos são extremamente longos, exigindo profundo domínio das capacidades cognitivas em relação à leitura e interpretação. É indicado para professores e estudiosos da área da linguagem com o objetivo de promover uma prática de ensino mais significativa. 